\title{
PENGARUH KECEMASAN TERHADAP PENYESUAIAN PERNIKAHAN PADA WANITA PERIMENOPAUSE
}

\author{
Ivana Kamilie $^{1}$, Rismiyati E. Koesma ${ }^{2}$, dan Zamralita ${ }^{3}$ \\ ${ }^{1}$ Program Studi Psikologi Profesi, Universitas Tarumanagara, Jakarta \\ Email: ivana.717181007@stu.untar.ac.id \\ ${ }^{2}$ Fakultas Psikologi, Universitas Tarumanagara, Jakarta \\ Email:tettyris23@gmail.com \\ ${ }^{3}$ Fakultas Psikologi, Universitas Tarumanagara Jakarta \\ Email: zamralita@fpsi.untar.ac.id
}

\begin{abstract}
Physical decline will occur gradually in middle adulthood. One of the big things related to the physical condition of middle adult women is the period of perimenopause. Not only physically, the perimenopause period will also affect the emotional aspects of women. In this period, women will experience a higher level of anxiety rather than other developmental periods. The anxiety experienced not only affects the individual, but can also have an impact on the couple, such as affecting marriage satisfaction, marriage quality, and sexual satisfaction. One term that is quite broad and can summarize these aspects is marital adjustment. This study aims to determine the effect of anxiety on marital adjustment in perimenopause women. Participants in this study were 182 women, aged 40-50 years who experienced perimenopause symptoms (hot flashes, vaginal dryness, easy headaches, bone loss, increased levels of bad cholesterol, dry skin, difficulty concentrating, forgetfulness, decreased sexual desire and fertility, mood changes, irritability, increased symptoms of depression and anxiety). The measuring instruments used in this study were the State-Trait Anxiety Inventory (STAI) and the Dyadic Adjustment Scale (DAS). In this study, the analysis technique used is simple linear regression. The results showed a negative effect of anxiety on marriage adjustment $(B=-0.583, p<0.01)$. The higher the anxiety, the lower the marriage adjustment, and vice versa. The amount of influence given by anxiety on marital adjustment is $34 \%$.
\end{abstract}

Keywords: anxiety, marital adjustment, perimenopause

\begin{abstract}
ABSTRAK
Penurunan fisik akan terjadi secara bertahap pada masa dewasa madya. Salah satu hal besar yang berhubungan dengan kondisi fisik pada wanita dewasa madya adalah periode perimenopause. Tidak hanya berpengaruh secara fisik, periode perimenopause juga akan memengaruhi aspek emosional pada wanita. Pada periode ini, wanita akan mengalami tingkat kecemasan yang lebih tinggi dibandingkan pada masa perkembangan lainnya. Kecemasan yang dialami tidak hanya berdampak pada individu, namun juga dapat berdampak pada pasangan, seperti memengaruhi kepuasan pernikahan, kualitas pernikahan, dan kepuasan seksual, Salah satu istilah yang cukup luas dan dapat merangkum aspek-aspek terseut adalah penyesuaian pernikahan. Penelitian ini bertujuan untuk melihat pengaruh kecemasan terhadap penyesuaian pernikahan pada wanita perimenopause. Partisipan pada penelitian ini adalah 182 wanita, berusia 40-50 tahun yang mengalami simptom perimenopause (hot flashes, rasa kering pada vagina, mudah sakit kepala, pengeroposan tulang, peningkatan kadar kolesterol jahat, kulit kering, sulit berkonsenterasi, mudah lupa, penurunan gairah seksual dan kesuburan, perubahan kondisi mood, mudah tersinggung, peningkatan gejala depresi dan kecemasan). Alat ukur yang digunakan pada penelitian ini adalah State-Trait Anxiety Inventory (STAI) dan Dyadic Adjustment Scale (DAS). Pada penelitian ini teknik analisa yang digunakan adalah regresi linier sederhana. Hasil penelitian menunjukkan adanya pengaruh negatif kecemasan terhadap penyesuaian pernikahan $(B$ $=-0.583, \mathrm{p}<0.01)$. Semakin tinggi kecemasan maka penyesuaian pernikahan akan semakin rendah, dan sebaliknya. Adapun besar pengaruh yang diberikan kecemasan terhadap penyesuaian pernikahan adalah sebesar 34\%.
\end{abstract}

Kata Kunci: kecemasan, penyesuaian pernikahan, perimenopause

\section{PENDAHULUAN}

Spanier dan Cole (dalam Brandão, Brites, Pires, Hipólito, \& Nunes, 2019) mengatakan bahwa penyesuaian pernikahan adalah proses dalam pernikahan yang hasilnya ditentukan oleh adanya kesepakatan bersama, keeratan/kohesi hubungan, kepuasan hubungan, dan ekspresi afeksi satu sama lainnya. Berdasarkan definisi tersebut, penyesuaian pernikahan tidak sebatas hanya 
dilakukan pada pasangan yang baru menikah, namun merupakan hal yang penting dilakukan sepanjang pernikahan karena merupakan sebuah proses dalam pernikahan. Dapat dikatakan bahwa penyesuaian pernikahan adalah hal penting yang harus ada dalam setiap pernikahan. Jika pasangan dapat memiliki penyesuaian yang baik, maka hal tersebut akan meningkatkan kebahagiaan. Akan tetapi sebaliknya, jika pasangan tidak dapat memiliki penyesuaian dengan baik, kebahagiaan pasangan dapat menurun. Hal ini akan mengakibatkan terjadinya konflik yang berlarut-larut, kualitas pernikahan yang rendah, bahkan dapat memicu terjadinya perceraian (Sari \& Puspitawati, 2017).

Kondisi pernikahan dapat digambarkan berdasarkan angka perceraian yang terjadi dalam suatu wilayah. Di Indonesia, angka perceraian pada tahun 2017 sejumlah 364.163 pasangan dan mengalami peningkatan pada tahun 2018 menjadi 419.268 pasangan. Total ini merupakan angka perceraian pada pengadilan agama, belum termasuk data di pengadilan negeri. Berdasarkan angka tersebut, tidak dijelaskan secara rinci persentase dan rata-rata usia biologis maupun usia pernikahan yang mengalami terjadinya perceraian. Secara garis besar, Menteri Agama Lukman Hakim Saifudin periode 2014-2019 menyebutkan, bahwa perceraian terjadi lebih banyak pada usia pernikahan di bawah 5 tahun, yang kebanyakan dilakukan oleh pasangan yang berusia di bawah 35 tahun. Walaupun demikian, jika ditelusuri satu per satu hasil Pengadilan Agama maupun putusan Mahkamah Agung, akan ditemukan bahwa perceraian dapat terjadi pada berbagai rentang usia, bahkan pada usia pernikahan di atas 25 tahun, yaitu pada kelompok usia dewasa madya (Amin, 2019).

Secara teoritis, pada usia dewasa madya, pasangan sudah semakin mengenal satu sama lain dan pernikahan cenderung lebih stabil (Santrock, 2016). Gorchoff, John, dan Helson (dalam Santrock, 2016) menyebutkan pada usia dewasa madya, kepuasan pernikahan mengalami peningkatan. Adanya perceraian yang terjadi walaupun tidak sebanyak pada usia pernikahan muda, tidak berbanding lurus dengan pernyataan ahli mengenai kestabilan dan kepuasan pernikahan. Hal tersebut menunjukkan bahwa pada usia dewasa madya, penyesuaian pernikahan harus tetap ada sehingga konflik yang berlarut dan perceraian dapat diminimalisir.

Jika dikaitkan dengan tugas perkembangan pada dewasa madya mengenai konflik yang dapat terjadi dengan faktor usia, Papalia dan Feldman (2015), mengatakan orang-orang dewasa madya cenderung mengalami tingkat stres yang lebih tinggi dan lebih sering dengan berbagai jenis stres daripada orang dewasa yang lebih muda atau lebih tua. Stressor utama yang terjadi erat kaitannya dengan hubungan keluarga, pekerjaan, uang, dan rumah tangga. Stres juga dapat terjadi karena adanya perubahan peran, seperti transisi karir, anak tumbuh dan meninggalkan rumah dan renegosiasi hubungan keluarga. Seringnya memiliki ketegangan interpersonal, seperti berargumen dengan suami, menurun seiring bertambahnya usia, namun stressor lain seperti teman atau kerabat yang sakit menjadi meningkat. Stressor yang meningkat berbanding terbalik dengan kondisi fisik yang dialami oleh orang pada dewasa madya. Perubahan fisik pada dewasa madya terjadi secara bertahap (gradual) mengalami penurunan, seperti pada aspek sensori, kesehatan, stamina, dan kekuatan sehingga memengaruhi kesehatan fisik dewasa madya (Papalia \& Feldman, 2015). Penurunan fisik pada dewasa madya lebih signifikan dialami oleh wanita. Papalia dan Feldman mengatakan bahwa salah satu hal besar yang dialami oleh wanita pada dewasa madya yang berhubungan dengan kesehatan karena erat kaitannya dengan periode menopause. Kesehatan wanita mulai menunjukkan penurunan pada masa periode perimenopause. 
World Health Organization (1996) mendefinisikan perimenopause sebagai periode yang mencakup beberapa waktu sebelum menopause (ketika fitur endokrinologis, biologis, dan klinis mendekati menopause dimulai) dan tahun pertama setelah menopause. Perbedaan transisi waktu menopause berbeda-beda. World Health Organization (1996) mengatakan 2-8 tahun, Papalia dan Feldman (2015) mengatakan 3-5 tahun, atau Willy (2019) mengatakan 4-10 tahun. Secara umum, perimenopause dimulai pada usia 40 tahun wanita, meskipun mungkin saja dimulai pada usia 30 tahun (The American College of Obstetricians and Gynecologists, 2018). Pada masa ini terjadi berbagai macam tanda yang dialami wanita, seperti masalah fisik (hot flashes, rasa kering pada vagina, mudah sakit kepala, pengeroposan tulang, peningkatan kadar kolesterol jahat, kulit kering), masalah kognitif (sulit berkonsenterasi, mudah lupa), masalah seksual (penurunan gairah seksual dan kesuburan), dan masalah psikologis (perubahan kondisi mood, mudah tersinggung, peningkatan gejala depresi dan kecemasan) (The American College of Obstetricians and Gynecologists, 2018; Willy, 2019; Sartika, 2019).

Peneliti melakukan studi awal kepada 41 wanita yang berada pada periode perimenopause (usia 40-50 tahun), untuk melihat jenis kecemasan yang terjadi. Sebesar 19\% wanita perimenopause memiliki kecemasan terhadap permasalahan seksual, 33\% terhadap permasalahan psikologis seperti mudah cemas, mudah marah, perubahaan mood, dan depresi, dan $48 \%$ terhadap permasalahan fisik seperti kulit tidak elastis, kulit kering, payudara kendur, rambut rontok, dan berat badan bertambah.

Kecemasan adalah hal yang wajar, dapat dialami oleh siapa saja dan merupakan respon adaptasi dari situasi atau stimulus yang dianggap membahayakan diri. Akan tetapi, jika kecemasan menjadi berlebihan, seperti yang banyak dialami oleh wanita pada masa perimenopause (FloresRamos, Tomassoni, Guerrero-López, \& Salinas, 2017), hal ini tidak hanya berdampak negatif pada dirinya saja. Kondisi kecemasan yang berlebih dapat berpengaruh dalam aspek sosial, seperti pada penelitian yang dilakukan oleh Stokes (2017) bahwa simptom kecemasan akan memengaruhi pasangan mereka yang dapat berdampak pada pernikahan.

Beberapa penelitian mengatakan bahwa kecemasan dapat berpengaruh pada beberapa istilah yang berhubungan dengan pernikahan, seperti kepuasan pernikahan (Maroufizadeh, Hosseini, Foroushani, Omani-Samani, \& Amini, 2018) dan kualitas pernikahan (Gamliel, Dollberg, \& Levy, 2018). Salah satu istilah yang cukup luas dan merangkum aspek yang telah disebut di atas adalah penyesuaian pernikahan. Brandão, Brites, Pires, Hipólito, dan Nunes (2019) melakukan studi yang dilakukan kepada pasangan yang sedang hamil menemukan bahwa kecemasan berhubungan negatif dengan penyesuaian pernikahan. Semakin cemas baik istri maupun suami, akan memengaruhi penyesuaian pernikahan. Hubungan antara kecemasan dan penyesuaian pernikahan juga dapat dilihat dari penelitian Whisman et al. (2018) yang menemukan bahwa terdapat hubungan negatif antara penyesuaian pernikahan dengan simptom depresi dan simptom kecemasan pada partisipan dewasa kembar dengan pasangannya.

Walaupun beberapa penelitian memperlihatkan hubungan negatif antara kecemasan wanita dan penyesuaian pernikahan, namun hasil itu tidak sesuai dengan penelitian terbaru yang dilakukan oleh Rawal (2020). Rawal melakukan penelitian mengenai hubungan antara kecemasan dan penyesuaian pernikahan pada wanita. Hasilnya tidak ada hubungan yang signifikan antara kecemasan dan penyesuaian pernikahan.

Melihat perbedaan hasil penelitian pada penelitian terdahulu, peneliti ingin menguji lebih lanjut pengaruh antara kecemasan terhadap penyesuaian pernikahan. Peneliti ingin memperjelas hasil 
antara kedua variabel tersebut dengan dugaan bahwa kecemasan memiliki pengaruh negatif terhadap penyesuaian pernikahan. Kecemasan yang akan dilihat pada penelitian ini merupakan state anxiety karena peneliti hanya ingin melihat kecemasan yang berlangsung saat ini pada wanita yang berada pada masa perimenopause, bukan melihat kecemasan bawaan (trait anxiety). Alasan peneliti hanya mengukur state anxiety karena berdasarkan pada penelitian Flores-Ramos, Tomassoni, Guerrero-López, dan Salinas (2017), perimenopause hanya berhubungan tinggi dengan state anxiety. Adapun definisi dari state anxiety adalah suatu keadaan emosional sementara yang muncul pada situasi-situasi tertentu dan ditandai dengan munculnya reaksi fisiologis dan persepsi subjektif terhadap ketegangan dan kekhawatiran akan bahaya atau ancaman yang terdapat pada situasi tersebut (Spielberger, 1972). Hipotesis pada penelitian ini adalah terdapat pengaruh negatif antara kecemasan (state anxiety) terhadap penyesuaian pernikahan wanita perimenopause.

\section{METODE PENELITIAN}

Karaktristik partisipan pada penelitian ini adalah wanita yang berada dalam rentang usia 40-50 tahun, memiliki ikatan pernikahan, dan menunjukkan satu atau lebih gejala/simptom perimenopause. Adapun gejala-gelaja yang dapat terjadi adalah masalah fisik (hot flashes, rasa kering pada vagina, mudah sakit kepala, pengeroposan tulang, peningkatan kadar kolesterol jahat, kulit kering), masalah kognitif (sulit berkonsenterasi, mudah lupa), masalah seksual (penurunan gairah seksual dan kesuburan), dan masalah psikologis (perubahan kondisi mood, mudah tersinggung, peningkatan gejala depresi dan kecemasan) (Willy, 2019; Sartika, 2019; The American College of Obstetricians and Gynecologists, 2018). Teknik pengambilan sampel yang digunakan pada penelitian ini adalah snowball sampling. Teknik ini dirasa tepat untuk dilakukan karena peneliti memiliki keterbatasan akses untuk mencari partisipan wanita perimenopause dengan rentang usia 40-50 tahun. Peneliti mendapat informasi mengenai akses partisipan selanjutnya dari partisipan yang sudah mengisi kuesioner. Hasil yang didapat dengan teknik ini, peneliti mendapat jumlah partisipan yang awalnya sedikit, namun semakin lama semakin besar karena akses partisipan yang telah ditemui sebelumnya.

Partisipan penelitian ini berjumlah 182 wanita yang berada pada rentang usia 40-50 tahun (berada dalam masa perimenopause), dengan persentase usia 40 tahun (20,9\%), 41 tahun $(10,4 \%), 42(11,5 \%), 43$ tahun $(6,6 \%), 44$ tahun $(4,9 \%), 45$ tahun $(6,6 \%), 46$ tahun $(2,2 \%), 47$ tahun $(6,6 \%), 48$ tahun $(8,2 \%), 49$ tahun $(3,8 \%), 50$ tahun $(18,1 \%)$. Berdasarkan jenis pekerjaan, IRT $(59,3 \%)$, karyawan swasta $(10,4 \%)$, wirausaha $(11,0 \%)$, guru $(13,7 \%)$, lainnya $(5,5 \%)$. Berdasarkan agama, Islam (50,5\%), Kristen (36,3\%), Katolik (12,6\%), dan Buddha $(0,5 \%)$. Berdasarkan usia pernikahan, 1-5 tahun (3,8\%), 6-10 tahun (10,4\%), 11-15 tahun (26,4\%), 16-20 tahun $(25,8 \%), 21-25$ tahun $(18,1 \%), 26-30$ tahun $(13,7 \%),>30$ tahun $(1,6 \%)$. Berdasarkan jumlah anak, jumlah yang tidak memiliki anak (6,6\%), 1 anak (15,4\%), 2 anak (36,8\%), 3 anak $(29,1 \%), 4$ anak (9,9\%), 5 anak 1,1), dan 6 anak $(1,1)$.

Peneliti menggunakan alat ukur State Trait Anxiety Inventory (STAI) untuk mengukur kecemasan pada wanita perimenopause. Alat ukur STAI merupakan pengukuran self-report yang terdiri dari 20 item yang dugunakan untuk mengukur dua konsep anxiety yang berbeda, yaitu state anxiety dan trait anxiety.

Alat ukur STAI pertama kali dibuat oleh Charles D. Spielberger, Richard L. Gosruch, dan Robert E. Lushene pada tahun 1964. Lebih dari 2.000 penelitian menggunakan STAI sejak muncul dalam literatur penelitian, tepatnya sejak STAI Test Manual diterbitkan (Spielberger et al., dalam 
Spielberger, 1983), termasuk studi dalam kedokteran, kedokteran gigi, pendidikan, psikologi, dan ilmu sosial lainnya.

Reliabilitas dan validitas alat ukur STAI sudah terbukti cocok serta adekuat untuk mengukur kecemasan, baik dalam setting penelitian maupun klinis. Spielberger (1983) menyebutkan reliabilitas pada alat ukur ini yang tinggi, yaitu 0.92 untuk state anxiety dan 0.90 untuk trait anxiety. Alat ukur ini juga sudah terbukti memiliki validitas concurrent, convergent, divergent, dan construct dari setiap skala. Seperti yang sudah dijelaskan sebelumnya bahwa peneliti hanya melakukan pengukuran pada state anxiety. Adapun nilai reliabilitas yang didapat peneliti $\alpha=$ 0.935 .

Tabel 1. Item alat ukur state trait anxiety inventory - state anxiety

\begin{tabular}{ccc}
\hline Skala & Nomor & Contoh Item \\
\hline State Anxiety & $1-20$ & Item 16: Saya merasa puas sekali \\
\end{tabular}

Skala State Anxiety terdiri dari 20 pernyataan yang mengevaluasi bagaimana perasaan partisipan "saat ini, saat ini." Terdapat empat pilihan yang paling menggambarkan keadaan sebenarnya saat ini: (1) tidak sama sekali; (2) agak; (3) cenderung; (4) sangat.

Setiap item STAI diberi skor 1 sampai 4, dengan skor 4 menunjukkan adanya tingkat kecemasan yang tinggi. Terdapat item reversed (unfavorable) pada STAI yang dihitung dengan membalikkan skor 1, 2, 3, atau 4 menjadi skor 4, 3, 2, atau 1. Skor total dilakukan dengan menjumlahkan seluruh skor pada 20 item sehingga skor yang didapat berada pada rentang 20 hingga 80 (Spielberger, 1983).

Alat ukur penyesuaian pernikahan yang digunakan pada penelitian ini adalah Dyadic Adjustment Scale (DAS) oleh Spanier (1976). Peneliti mendapatkan reliabilitas sangat baik $(\alpha=0.91)$, dengan reliabilitas masing-masing subskala sebesar 0.89 (dyadic consensus), 0.82 (dyadic satisfaction), 0.71 (dyadic cohesion), dan 0.62 (affectional expression).

Spanier (1976) juga mengatakan bahwa alat ukur ini juga memperlihatkan validitas konten, di mana item pada alat ukur ini dievaluasi berdasarkan langkah-langkah penyesuaian penyesuaian diad yang relevan untuk hubungan kontemporer (contemporary relationship), konsisten dengan definisi yang dibuat oleh Spanier dan Cole untuk penyesuaian dan komponennya (kepuasan, kohesi, dan konsensus), serta menggunakan kata-kata secara hati-hati dengan respons pilihan yang tepat. Validitas criterion-related terlihat dari item yang berkorelasi dengan external criterion seperti status pernikahan (menikah/bercerai) $(p<.001)$. Validitas konstruk pada item ini terlihat bahwa alat ukur DAS berkorelasi dengan alat ukur sejenis, yaitu Locke-Wallace Marital Adjustment Scale dengan nilai korelasi 0.86 pada partisipan menikah dan 0.88 pada partisipan yang bercerai $(p<0.01)$. Lebih lanjut lagi, validitas konstruk dapat dilihat dengan analisis faktor terhadap 32 item yang mengukur 4 komponen yang saling berhubungan dyadic consensus, dyadic satisfaction, dyadic cohesion, dan affectional expression. 
Tabel 2. Item alat ukur dyadic adjustment scale

\begin{tabular}{ccl}
\hline Skala & Nomor & \multicolumn{1}{c}{ Contoh Item } \\
\hline Dyadic Consensus & $1,2,3,5,7,8,9,10,11,12$, & Item 1: Penanganan keuangan keluarga \\
$13,14,15$ & \\
Dyadic Satisfaction & $16,17,18,19,20,21,22,23$, & $\begin{array}{l}\text { Item 16: Seberapa sering Anda } \\
\text { membahas atau pernahkah Anda } \\
\text { mempertimbangkan cerai, berpisah, } \\
\text { atau memutuskan hubungan Anda? }\end{array}$ \\
Dyadic Cohesion & 31,32 & $\begin{array}{l}\text { Item 24: Apakah Anda dan pasangan } \\
\text { memiliki minat yang sama? }\end{array}$ \\
Affectional Expression & $24,25,26,27,28$ & Item 4: Penunjukan kasih sayang \\
Subscale & $4,6,29,30$ & \\
\hline
\end{tabular}

Alat ukur ini diukur dengan skala Likert, dengan nilai skor yang berbeda. Rentang skor pada alat ukur ini dimulai dari 0 sampai 151. Adapun penilaian pada alat ukur DAS adalah sebagai berikut:

1. Item 1-15, diberikan skor 0-5 untuk pilihan selalu tidak setuju - selalu setuju.

2. Item 16-22, diberikan skor 0-5 untuk pilihan tidak pernah - selalu. Pada item nomor 16, 17, 20, 21, 22 dilakukan perhitungan skor secara terbalik (unfavorable).

3. Item 23-24, diberikan skor 0-4 untuk pilihan tidak pernah - setiap hari.

4. Item 25-28, diberikan skor 0-5 untuk tidak pernah - lebih sering.

5. Item 29-30 merupakan item unfavorable, sehingga diberikan 0 untuk jawaban ya dan 1 untuk jawaban tidak.

6. Item 31, diberikan skor 0-6, untuk jawaban sangat tidak bahagia - sempurna.

7. Item 32 , diberikan jawaban 0-5, untuk jawaban tidak ada yang bisa saya lakukan akan berusaha melakukan hampir segalanya.

\section{HASIL DAN PEMBAHASAN}

Berdasarkan rumus norma kategorisasi, kedua variabel yang dilibatkan dalam penelitian ini dikelompokkan ke dalam tiga kategori. Hasil perhitungan yang menghasilkan batasan-batasan skor variabel penyesuaian pernikahan dan kecemasan pada tiap-tiap kategori dapat dilihat pada Tabel 3.

Tabel 3. Norma kategorisasi variabel penelitian

\begin{tabular}{ccc}
\hline Kategori & Penyesuaian Pernikahan & Kecemasan \\
\hline Mean & 111.53 & 36.25 \\
Standar Deviasi & 19.24 & 12.28 \\
Tinggi $^{(*)}$ & $\mathrm{X} \geq 131$ & $\mathrm{X} \geq 48$ \\
Sedang $^{(*)}$ & $92 \leq \mathrm{X}<131$ & $24 \leq \mathrm{X}<48$ \\
Rendah $^{(*)}$ & $\mathrm{X}<92$ & $\mathrm{X}<24$ \\
\hline
\end{tabular}

Gambaran data penyesuaian pernikahan partisipan penelitian secara umum dapat dilihat pada Tabel 4. Berdasarkan norma kategorisasi telah diperoleh data bahwa partisipan dengan penyesuaian pernikahan kategori rendah berjumlah 24 (13.19\%), kategori sedang berjumlah 136 (74.73\%), dan kategori tinggi berjumlah 22 (12.09\%). Mayoritas partisipan penelitian memiliki penyesuaian pernikahan kategori sedang. Semakin tinggi skor penyesuaian pernikahan, maka semakin tinggi penyesuaian atau semakin rendahnya tingkat stres yang terjadi dalam pernikahan 
(Spanier, 1976). Pada penelitian ini dapat dikatakan bahwa mayoritas partisipan memiliki tingkat penyesuaian yang tidak terlalu tinggi maupun terlalu rendah.

Tabel 4. Gambaran data penyesuaian pernikahan

\begin{tabular}{cccc}
\hline Variabel & Tinggi & Sedang & Rendah \\
\hline \multirow{2}{*}{ Penyesuaian Pernikahan } & $\mathrm{n}: 22$ & $\mathrm{n}: 136$ & $\mathrm{n}: 24$ \\
& $(12.09 \%)$ & $(74.73 \%)$ & $(13.19 \%)$ \\
\hline
\end{tabular}

Gambaran penyesuaian pernikahan juga dapat dilihat berdasarkan keempat komponen, yaitu dyadic consensus, dyadic satisfaction, dyadic cohesion, dan affectional expression dapat dilihat pada Tabel 5.

Tabel 5. Gambaran komponen penyesuaian pernikahan

\begin{tabular}{lcccc}
\hline & $\begin{array}{c}\text { Jumlah } \\
\text { Item }\end{array}$ & Mean Skor Total / SD & $\begin{array}{c}\text { Nilai } \\
\text { Minimum }\end{array}$ & Nilai Maksimum \\
\hline Dyadic Consensus & 13 & Mean $=52.66$ & 10 & 65 \\
Dyadic Satisfaction & 10 & $\begin{array}{c}\mathrm{SD}=8.60 \\
\text { Mean }=34.27\end{array}$ & 4 & 49 \\
Dyadic Cohesion & 5 & $\begin{array}{c}\mathrm{SD}=7.89 \\
\text { Mean }=14.90 \\
\mathrm{SD}=5.35\end{array}$ & 0 & 24 \\
Affectional Expression & 4 & $\begin{array}{c}\text { Mean }=9.70 \\
\mathrm{SD}=1.97\end{array}$ & 4 & 12 \\
\hline
\end{tabular}

Item-item dalam masing-masing komponen memiliki nilai skala yang berbeda. Oleh karena itu, peneliti tidak melihat lebih lanjut mengenai prioritas komponen dari penyesuaian pernikahan yang dimiliki oleh partisipan penelitian.

Adapun gambaran kecemasan pada partisipan yang merupakan wanita perimenopause, 33 partisipan (18.13\%) berada pada kategori rendah dan 33 partisipan $(18.13 \%)$ berada pada kategori tinggi. Mayoritas partisipan, yaitu sebanyak 116 partisipan (63.74\%) berada pada kategori sedang. Semakin tinggi skor partisipan, maka tingkat kecemasan yang dimiliki individu tersebut semakin tinggi. Sebaliknya, semakin rendah skor partisipan, semakin rendah pula kecemasan yang dimiliki individu (Spielberger, 1972). Gambaran kecemasan pada penelitian ini dapat dilihat pada Tabel 6 .

Tabel 6. Gambaran kecemasan

\begin{tabular}{cccc}
\hline Variabel & Tinggi & Sedang & Rendah \\
\hline \multirow{2}{*}{ Kecemasan } & $\mathrm{n}: 33$ & $\mathrm{n}: 116$ & $\mathrm{n}: 33$ \\
& $(18.13 \%)$ & $(63.74 \%)$ & $(18.13 \%)$ \\
\hline
\end{tabular}

Kecemasan berpengaruh secara negatif dan signifikan terhadap penyesuaian pernikahan $(B=-$ $0.583, \mathrm{p}<0.01)$. Hal ini menyatakan bahwa semakin tinggi kecemasan seseorang, maka penyesuaian pernikahan orang tersebut akan lebih rendah. Sebaliknya, semakin rendah kecemasan seseorang, maka penyesuaian orang tersebut akan semakin tinggi. Adanya hasil ini menyatakan bahwa hipotesis pertama pada penelitian ini diterima.

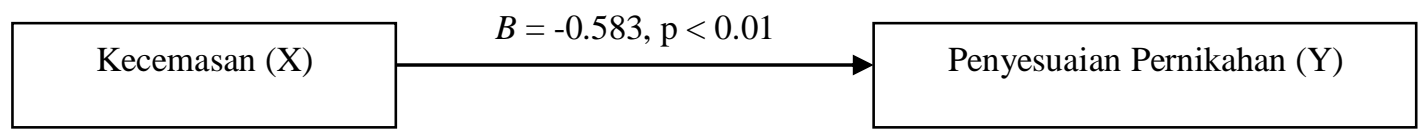

Gambar 1. Pengaruh kecemasan terhadap penyesuaian pernikahan 
Perlu diketahui bahwa penyesuaian pernikahan yang diambil pada penelitian ini adalah sebuah "potret" pada masa perimenopause sehingga hasil penelitian ini merupakan evaluasi karakteristik dan interaksi pernikahan yang berfokus pada kualitas hubungan disaat pengambilan data. Mayoritas partisipan pada penelitian ini memiliki tingkat penyesuaian pernikahan dalam kategori sedang. Spanier (1976) mengklasifikasikan individu distres jika memiliki skor $\leq 101$ dan individu nondistres jika memiliki skor di atas 102. Pada penelitiannya didapatkan rata-rata skor individu yang menikah adalah 114.8 dan individu yang bercerai 70.7. Namun pada penelitian ini, sesuai dengan norma kategorisasi variabel penyesuaian pernikahan, klasifikasi sedang berada pada rentang 92 - 131 dengan rata-rata skor 111.53. Dapat diartikan, mereka mampu untuk mengontrol stres yang terjadi dalam pernikahan sehingga tingkat penyesuaian pernikahan menjadi lebih baik.

Partisipan pada penelitian ini mayoritas memiliki kecemasan dalam kategori sedang. Hal ini tidak sesuai dengan temuan Flores-Ramos, Tomassoni, Guerrero-López, dan Salinas (2017) yang menemukan, state anxiety yang sangat tinggi sangat berhubungan dengan wanita perimenopause. Mereka mengevaluasi skor sejak Maret sampai September 2013. Tinggi dan rendahnya state anxiety dapat berubah dari hari ke hari. Hal ini dapat menjadi salah satu evaluasi pada penelitian ini karena hanya mengukur state anxiety hanya pada satu waktu (tidak longitudinal).

Hasil korelasi kedua variabel tersebut memperlihatkan bahwa kecemasan berpengaruh negatif dengan penyesuaian pernikahan. Hasil ini sesuai dengan penelitian sebelumnya yang dilakukan oleh Brandão, Brites, Pires, Hipólito, dan Nunes (2019) pada pasangan yang sedang hamil. Penelitian lain yaitu, Whisman et al. (2018) yang menemukan bahwa terdapat hubungan negatif antara penyesuaian pernikahan dengan simptom depresi dan simptom kecemasan pada studi wanita/pria kembar dan pasangannya dengan rata-rata usia dewasa madya. Selain itu, Abbas, et al. (2019) melihat hubungan negatif yang terjadi penyesuaian pernikahan dengan depresi dan kecemasan pada wanita yang bekerja dan tidak bekerja dengan rentang usia 20-60 tahun. Semakin cemas istri, maka kualitas penyesuaian pernikahan akan lebih rendah. Hasil ini menyatakan bahwa pengaruh negatif kecemasan dan penyesuaian pernikahan berlaku pada setiap usia, termasuk pada usia perimenopause.

Penelitian mengenai perimenopause tidak banyak dilakukan di Indonesia, sehingga referensi mengenai penelitian perimenopause di Indonesia hanya sedikit didapatkan. Penelitian ini dapat menjadi pemicu untuk penelitian lain, seperti untuk melihat gejala-gejala lain yang terjadi di masa perimenopause. Banyak aspek yang dapat digali pada masa perimenopause yang terjadi pada wanita dewasa madya. Secara khusus, penyesuaian pernikahan juga menjadi topik yang menarik, bahwa peneliti tidak hanya meneliti variabel ini pada pasangan muda, namun penyesuaian pernikahan merupakan proses berkelanjutan yang terjadi dalam sepanjang pernikahan.

Walaupun demikian, masih banyak hal yang perlu untuk ditambahkan dalam penelitian ini agar penelitian selanjutnya menjadi lebih baik. Faktor-faktor yang memengaruhi pernyesuaian pernikahan seperti bentuk cinta dan kesehatan perlu menjadi pertimbangan dalam penelitian selanjutnya. Selain itu, variabel penyesuaian pernikahan akan lebih baik jika diukur secara dyadic dengan melibatkan pasangan. Pengukuran dari dua pihak (subjek dan pasangan) dapat lebih menggambarkan variabel-variabel tersebut dan memperkaya hasil seperti dapat mengetahui bagaimana sikap pasangan terhadap wanita yang berada pada masa perimenopause. 


\section{KESIMPULAN DAN SARAN}

Kasus perceraian yang terjadi di Indonesia, dapat menggambarkan penyesuaian pernikahan yang terjadi. Setiap tahun angka perceraian di Indonesia semakin bertambah yang tidak hanya terjadi pada pasangan dewasa muda, namun dapat terjadi pada pasangan dewasa madya (Amin, 2019). Secara teori sebenarnya pernikahan di usia dewasa madya menunjukkan adanya kestabilan dan kepuasan pernikahan (Santrock, 2016), namun ada beberapa aspek yang dapat memengaruhi yaitu tingkat stres dan perubahan fisik (Papalia \& Feldman, 2015). Pada penelitian ini, peneliti mengacu kepada perubahan aspek yang terjadi, terutama pada wanita dewasa madya, yaitu masa perimenopause. Penelitian-penelitian terdahulu memperlihatkan tingginya kecemasan yang dialami wanita perimenopause. Hal ini bukan hanya berdampak pada dirinya sendiri, namun juga terhadap pasangan. Hasil dari penelitian ini menunjukkan adanya pengaruh negatif dan signifikan antara kecemasan sebagai variabel independent terhadap penyesuaian pernikahan sebagai variabel dependent. Hipotesis dalam penelitian ini diterima dan menunjukkan nilai $B=-$ $0.583, \mathrm{p}<0.01$. Selanjutnya, diperlukan penelitian lanjutan dengan mempertimbangkan faktorfaktor yang dapat memengaruhi penyesuaian pernikahan dan pentingnya mengukur penyesuian pernikahan secara dyadic.

Penyesuaian pernikahan merupakan suatu hal terus dilakukan sepanjang pernikahan. Hasil dari penelitian ini menunjukkan bahwa terdapat pengaruh kecemasan terhadap penyesuaian pernikahan pada masa perimenopause. Jika kecemasan wanita perimenopause meningkat, maka penyesuaian pernikahan menjadi lebih rendah. Oleh karena itu, penting untuk memperhatikan tingkat kecemasan yang dimiliki oleh individu, dalam hal ini wanita perimenopause. Selfawareness menjadi penting agar kecemasan individu tidak terlalu tinggi dan berdampak pada hubungan pernikahan.

Banyak orang mengetahui istilah menopause, namun hanya sedikit orang yang mengetahui istilah perimenopause. Pada partisipan dalam penelitian ini, hanya 18 partisipan (10\%) yang menjawab istilah ini dengan benar, 9 partisipan (5\%) menjawab salah, dan 155 partisipan (85\%) memilih untuk menjawab tidak mengetahui istilah perimenopause. Penting untuk mengetahui istilah perimenopause agar wanita dewasa madya dapat memahami kondisi dan simptom yang dapat terjadi ketika berada dalam fase ini. Oleh karena itu, perlu dilakukan edukasi dari psikolog, dokter atau akademisi kepada masyarakat terutama wanita agar memahami fase menopause secara utuh (premenopause, perimenopause, dan menopause).

Bagi wanita dewasa madya yang sedang berada dalam fase perimenopause dan mengalami simptom yang mengganggu aktivitas sehari-hari dapat meminta bantuan ahli. Memiliki teman yang seusia juga dapat menjadi solusi lain untuk bertukar cerita pengalaman yang dialami pada fase ini. Pasangan juga perlu untuk memahami kondisi yang dialami oleh wanita perimenopause sehingga dapat meringankan simptom yang terjadi.

\section{Ucapan Terima Kasih (Acknowledgement)}

Peneliti mengucapkan terima kasih Tuhan yang Maha Esa, Universitas Tarumanagara, dan juga kepada partisipan pada penelitian ini.

\section{REFERENSI}

Abbas, J., Aqeel, M., Abbas, J., Shaher, B., A., J., Sundas, J., \& Zhang, W. (2019). The moderating role of social support for marital adjustment, depression, anxiety, and stress: Evidence from Pakistani working and nonworking women. Journal of Affective Disorders, 244, 231-238. doi: 10.1016/j.jad.2018.07.071 
Amin, N. (2019, Agustus 19). Pembinaan keluarga sakinah berbasis masjid/musholla. Bimas Islam. https://bimasislam.kemenag.go.id/post/opini/pembinaan-keluarga-sakinahberbasis-masjidmusholla

Brandão, T., Brites, R., Pires, M., Hipólito, J., \& Nunes, O. (2019). Anxiety, depression, dyadic adjustment, and attachment to the fetus in pregnancy: Actor-partner interdependence mediation analysis. Journal of Family Psychology,33(3), 294-303. doi: 10.1037/fam0000513

Flores-Ramos, M., Tomassoni, R. S., Guerrero-López, J. B., \& Salinas, M. (2017). Evaluation of trait and state anxiety levels in a group of peri- and postmenopausal women. Women \& Health, 58(3), 305-319. doi: 10.1080/03630242.2017.1296059

Gamliel, K. H., Dollberg, D. G., \& Levy, S. (2018). Relations between parents' anxiety symptoms, marital quality, and preschoolers' externalizing and internalizing behaviors. Journal of Child and Family Studies, 27(12), 3952-3963. doi: 10.1007/s10826-0181212-3

Papalia, D. E., \& Feldman, R. D. (2015). Experience human development. New York: McGrawHill.

Maroufizadeh, S., Hosseini, M., Foroushani, A. R., Omani-Samani, R., \& Amini, P. (2018). Application of the dyadic data analysis in behavioral medicine research: Marital satisfaction and anxiety in infertile couples. BMC Medical Research Methodology, 18(1), 1-10. doi: 10.1186/s12874-018-0582-y

Rawal, S. (2020). Marital satisfaction among females: Effect of anxiety on overall happiness. International Journal of Information Movement, 5(4), 14-19. http://www.ijim.in/wp-content/uploads/2020/09/Vol-5-Issue-V-15-17-paper-3-sudeshrawal-MARITAL-SATISFACTION-AMONG-FEMALES.pdf

Santrock, J. W. (2016). Essentials of life-span development (5th ed.). New York: McGraw-Hill.

Sari, D. P., \& Puspitawati, H. (2017). Family conflict and harmony of farmers family. Journal of Family Sciences, 2(1), 28-41. https://media.neliti.com/media/publications/279468family-conflict-and-harmony-of-farmers-f-0d964e7b.pdf

Sartika, R. E. A. (2019, Mei 29). Memasuki masa menopause, apa yang terjadi pada tubuh perempuan?. Kompas. https://sains.kompas.com/read/2019/05/29/160400523/memasukimasa-menopause-apa-yang-terjadi-pada-tubuh-perempuan-?page=all

Spanier, G. B. (1976). Measuring dyadic adjustment: New scales for assessing the quality of marriage and similar dyads. Journal of Marriage and the Family, 38(1), 15. doi: $10.2307 / 350547$

Spielberger, C. D. (1972). Anxiety: Current trends in theory and research on anxiety. New York: Academic Press.

Spielberger, C. D. (1983). State-trait anxiety inventory for adults. California: Mind Garden, Inc.

Stokes, J. E. (2017). Mutual influence and older married adults' anxiety symptoms: Results from the Irish longitudinal study on ageing. The Gerontologist, 1-11. doi: 10.1093/geront/gnv147

The American College of Obstetricians and Gynecologists. (2018, Desember). The menopause years. The American College of Obstetricians and Gynecologists. https://www.acog.org/Patients/FAQs/The-Menopause-Years?IsMobileSet=false

Willy, T. (2019, Juni 28). Perimenopause. Alodokter. https://www.alodokter.com/perimenopause

Whisman, M. A., Pont, A. D., Rhee, S. H., Spotts, E. L., Lichtenstein, P., Ganiban, J. M., ... Neiderhiser, J. M. (2018). A genetically informative analysis of the association between dyadic adjustment, depressive symptoms, and anxiety symptoms. Journal of Affective Disorders, 237, 18-26. doi: 10.1016/j.jad.2018.04.105 
World Health Organization. (1996). The world health report: Fighting disease forstering development. Geneva: WHO Library Cataloguing in Publication Data. 